\title{
Agile Development of a Flipped Classroom Course
}

\author{
Linda Blömer ${ }^{(\bowtie)}$, Christin Voigt ${ }^{(\bowtie)}$, Alena Droit ${ }^{(\bowtie)}$, \\ and Uwe Hoppe ${ }^{(\bowtie)}$ \\ Osnabrueck University, Katharinenstr. 3, 49074 Osnabrueck, Germany \\ \{linda.bloemer, christin. voigt, alena.droit, \\ uwe.hoppe\}@uni-osnabrueck.de
}

\begin{abstract}
Digital course designs such as the Flipped Classroom (FC) are increasingly enriching university education. However, before implementing such an FC, teachers face the challenge of creating content in the form of materials and activities and finding a suitable development method. This is very time-consuming, which is why circumstances such as lack of time and personnel can make implementation difficult. In other areas, agile approaches have already proven to be effective in enabling flexible and efficient development. We use this opportunity to overcome different barriers in the context of FC development by creating an agile model for FC development. To achieve this, we first examined the previous research on agile development approaches concerning the implementation of an FC by a systematic literature review, concluding that no appropriate model exists yet. Building upon this, we designed an Agile $^{\mathrm{FC}}$ Development Model, which can be used by teachers to create their FC. This model is very generally designed so that it can be easily adopted. On the other hand, it can be adjusted to a particular situation without effort. We also illustrate the application of the model using a small case study.
\end{abstract}

Keywords: Agile development $\cdot$ Case study $\cdot$ Flipped classroom $\cdot$ Model

\section{Introduction}

The Flipped Classroom (FC), also known as the inverted classroom, has become an increasingly popular teaching method in Higher Education Institutions (HEI) throughout the last decade. It can generally be described as the swapping of traditional attendance time activities with at-home activities [1]. Direct computer-based instructions like videos are used to convey knowledge at home before students apply and deepen their knowledge in interactive activities inside the classroom [2]. Many studies report positive effects of FC teaching, like improved learning performance and increased student engagement [3]. However, the development of an FC is a challenging task, where different barriers can occur, such as lack of time [4] or the need for technical and media didactic support [5]. FCs always contain an online and offline part, which has to be synchronized. The development of videos, self-assessment tests, and other online content is more time consuming than preparing a traditional lecture [3]. Also, for the interactive attendance part of a class, various active teaching methods 
should be used, and new contents have to be created. Teachers can feel overwhelmed when they create FCs. A possible resistance of the teachers concerned about the effort and technical challenges involved should also be taken into account. In order to overcome these barriers, a feasible and efficient approach to FC development is required. At this point, agile methods can offer a solution. The concept of agility became quite common when the Manifesto for Agile Software Development was published in 2001. It stated that the development of software could be improved if the development process focuses on four principles: Individuals and interaction, working software, customer collaboration, and responding to change [6]. Even though some authors state that the current principles of agility often lack transferability outside the field of software development, the underlying concepts of agility, flexibility, and leanness, can be easily transferred to other fields [7]. Tesar and Sieber adapted the agile principles for the field of agile e-learning development, leading to the four core principles: Personalized learning process, the usability of learning utilities, learner-centered design, and flexible course design [8]. Agile methods can empower HEIs to implement new teaching methods in an efficient and cost-reducing way [9] and can lead to an improvement in the flexibility and reactivity of the capable stakeholders [10]. The added value of agile methods in teaching and pedagogy has already become clear in previous studies [11]. Besides, it is recommended to implement an FC step by step, starting with the transformation of single lectures as pilots instead of transforming the whole lecture at once [12, 13]. With this iterative procedure, teachers can assess, compare, and continually improve future FC lectures through regular evaluations [12, 14]. In order to limit the workload and consider students' opinions, teachers can also involve students to support FC development [13]. The Horizon Report highlighted the application of agile approaches as a long-term key trend to drive the change concerning technology adaption in 2014 [9]. Surprisingly, there has been very little isolated research on the use of agile methods to develop an FC so far. A transferable model showing an agile FC development process is still lacking. Therefore, it is our goal to give teachers and other stakeholders of different disciplines an overview and a recommendation on agile FC development to facilitate FC implementation and break down barriers. To achieve this, we give an overview of the previous research in this area, design a general model for agile FC development, and describe the application of the model in a case study. Thus, this paper addresses the following research questions (RQ): (1) Which concepts of agile methods are already used in the context of FC development according to current research? (2) How could a process model for agile FC development look like? (3) How could an FC be implemented step by step, taking into account this agile development model? Figure 1 shows an overview of the systematic procedure of this article, including the research process and the corresponding paper structure.

\begin{tabular}{|c|c|c|c|c|c|c|}
\hline \multicolumn{2}{|l|}{$\begin{array}{l}\text { Research } \\
\text { Process }\end{array}$} & \multicolumn{2}{|c|}{$\begin{array}{l}\text { Literature Review } \\
\text { Agile Concepts for FC Development }\end{array}$} & \multirow{2}{*}{\begin{tabular}{|c|}
$\begin{array}{l}\text { Model Design } \\
\text { Agile }^{\mathrm{FC}} \text { Development Model }\end{array}$ \\
Section 4: \\
Design of an Agile \\
Development Model
\end{tabular}} & \multicolumn{2}{|c|}{$\begin{array}{l}\text { Case Study } \\
\text { Prototyp of Agile } \mathrm{e}^{\mathrm{FC}} \text { Development }\end{array}$} \\
\hline $\begin{array}{l}\text { Paper } \\
\text { Structure }\end{array}$ & $\begin{array}{l}\text { Section 1: } \\
\text { Introduction }\end{array}$ & $\begin{array}{l}\text { Section 2: } \\
\text { Method }\end{array}$ & $\begin{array}{c}\text { Section 3: } \\
\text { Findings } \\
\text { in Literature Review }\end{array}$ & & $\begin{array}{c}\text { Section 5: } \\
\text { Application } \\
\text { of the Model in Practice }\end{array}$ & $\begin{array}{l}\text { Section 6: } \\
\text { Conclusion }\end{array}$ \\
\hline
\end{tabular}

Fig. 1. Systematic procedure 
As shown in Fig. 1, systematic literature research serves as the foundation of our paper, answering RQ1 in Sect. 2. Based on the results and current research about the determined agile concepts presented in Sect. 3, we then develop and explain our general Agile ${ }^{\mathrm{FC}}$ Development Model in Sect. 4, giving a response to RQ2. Afterward, we apply the model in practice by showing the use in a module of a bachelor's degree program at a German public university. By giving an insight into the current and planned implementation of this FC, we answer RQ3.

\section{Method}

In order to find out which agile methods have already been used for FC development in the current literature, we conducted a literature review and used the results to design an agile FC development model. This model was then applied in a case study. The literature review and its phases search and assessment, interpretation, synthesis, guidance and conclusion [15] build the basis of our work. While the search and assessment process are explained below and outlined in Fig. 2, the other phases of the literature review are included in the following sections.

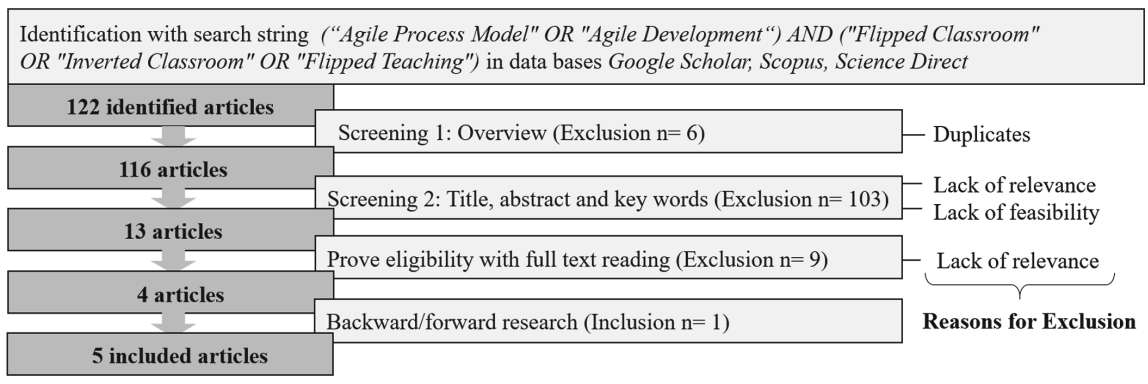

Fig. 2. Search and assessment process

The search was carried out systematically [16] under consideration of defining rules as reasons for stepwise exclusion. The search string shown in Fig. 2 leads to a total of 122 identified articles. We focused our search on the intersection between agile process models or agile development mentioned in research so far and the environment of the FC or similar. A focus on these topics in the investigated articles represents the inclusion criteria in our search and assessment process. On the other hand, we defined duplicates, lack of relevance, and lack of feasibility as exclusion criteria, which are explained in more detail below. We used the data bases Google Scholar, Science Direct, AISnet, Eric, Web of Science, and Scopus for our research. However, AISnet, Eric, and Web of Science did not deliver any results, which is why the results shown refer to Google Scholar, Science Direct, and Scopus. After the first screening, we removed all duplicates, which was necessary if an article was listed several times on different data bases. Thus, 116 articles remained for screening 2 in which title, abstract, and keywords are viewed. For the second screening, we defined the reasons for 
exclusion due to lack of relevance or lack of feasibility. We excluded articles due to a lack of relevance if they did not show reference to agile process models or agile development in the context of FC course development. However, we included those articles, which refer to agile process models or agile development in the context of blended learning or e-learning course development, if they show parallels, hints or outlooks on FC course development. Besides, reading the articles had to be classified as feasible. We excluded articles due to a lack of feasibility if they were written neither in English nor in German or were not available. As a result, 103 articles had to be excluded from screening 2 due to a lack of relevance or feasibility. Most of them showed a lack of relevance. After the second screening, 13 articles left for full-text reading to prove for eligibility, of which nine articles revealed a lack of relevance as stated above. In subsequent backward/forward research based on the remained articles, we looked for further sources dealing with agile process models or agile development in the context of FC, blended learning, or e-learning development. This search enabled us to identify another relevant article that we added to our study. Thus, the search and assessment process result in a total of five included articles. These articles form the basis for further development. In a team of three FC experienced researchers, we then carved out the used agile concept, the study design, and the primary goal mentioned in each text. Furthermore, we looked more closely at the concepts of agile development in each article. The findings are presented in the following section. After the literature review, we discussed the concepts and let selected aspects flow into our subsequent model in Sect. 4. Finally, we present a case study, which is based on the developed model and demonstrates the application in one FC lecture. Since three of the authors of this paper were involved in the implementation and, at the same time conduct research on the development model, we now make use of action research [17].

\section{Findings in Literature Review}

The literature review we conducted to answer our first research question resulted in five articles that deal with agile process models or agile development concerning FC course development. Table 1 gives an overview of the key aspects of the included articles, showing the agile concepts that have been used. It is striking how strongly most of the included articles differ concerning their concepts and their research background. The overview, sorted by year of publication, illustrates that no current articles could be found that were published after 2016. It seems surprising that no research has taken place in this field in recent years, although a need has been predicted [9]. Considering the agile concepts, it is also striking that just Scrum is used twice. The overview does not indicate that there is already an established concept or model for agile FC course development. The fact that most articles were conducted as case studies can be interpreted as further evidence that so far, mainly case-related models and concepts have been developed. The major goals of the articles shown in Table 1 focus on efficiency [6], individuality [18], flexibility [19], adaptability [20], and feasibility [4] of approaches or procedures creating digital media, digital materials or digital environments. The background and the implementation of the articles are versatile. 
Table 1. Included articles and their applied agile approaches

\begin{tabular}{l|l|l|l}
\hline $\begin{array}{l}\text { Author, Year } \\
\text { [Reference] }\end{array}$ & $\begin{array}{l}\text { Agile } \\
\text { concept }\end{array}$ & $\begin{array}{l}\text { Study } \\
\text { design }\end{array}$ & Major goal \\
\hline $\begin{array}{l}\text { Tesar and } \\
\text { Sieber [8] }\end{array}$ & $\begin{array}{l}\text { Agile } \\
\text { e-learning } \\
\text { development }\end{array}$ & $\begin{array}{l}\text { Literature } \\
\text { analysis }\end{array}$ & $\begin{array}{l}\text { Show an efficient procedure for responsible } \\
\text { persons putting blended learning into } \\
\text { practice }\end{array}$ \\
\hline $\begin{array}{l}\text { Meissner and } \\
\text { Stenger [18] }\end{array}$ & JiTT & $\begin{array}{l}\text { Case } \\
\text { study }\end{array}$ & $\begin{array}{l}\text { Demonstrate the use of digital media to } \\
\text { support the individual integration of } \\
\text { heterogeneous students at HEI }\end{array}$ \\
\hline $\begin{array}{l}\text { Vogel, Kilamo } \\
\text { and Kurti [19] }\end{array}$ & $\begin{array}{l}\text { Scrum \& } \\
\text { analogies to } \\
\text { JiTT }\end{array}$ & $\begin{array}{l}\text { Case } \\
\text { study }\end{array}$ & $\begin{array}{l}\text { Present a flexible approach to learning and } \\
\text { teaching, considering issues of work from } \\
\text { software employees }\end{array}$ \\
\hline Gale et al. [20] & Scrum & $\begin{array}{l}\text { Case } \\
\text { study }\end{array}$ & $\begin{array}{l}\text { Create a digital and adjustable learning } \\
\text { environment to school health staff in Africa } \\
\text { to fight against of Ebola }\end{array}$ \\
\hline Bofill [4] & $\begin{array}{l}\text { ADDIE \& } \\
\text { Rapid } \\
\text { prototyping }\end{array}$ & $\begin{array}{l}\text { Mixed } \\
\text { methods }\end{array}$ & $\begin{array}{l}\text { Present a feasible approach for medical } \\
\text { schools on how to create digital learning } \\
\text { materials }\end{array}$ \\
\hline
\end{tabular}

Tesar and Sieber claim that changing teacher roles and new digital learning and teaching opportunities place new demands on the development of a digitally improved course. Based on a literature analysis, they derived a framework of agile e-learning development from the Manifesto of Software development, containing transparency of expectations towards learners, possibility for individual learning, adaptability and usefulness of digital learning material, alignment of teaching with the need of learners as well as flexibility and adaptability of the course [8]. Meissner und Stenger, on the other hand, reports about students that differ from beginners to repeaters and experienced professionals in the subject Electrical Engineering at TU Nürnberg. Using Just in Time Teaching (JiTT), they offer a learner-centered and individual learning process [18]. JiTT is a teaching design that is based on questions provided online by the teacher, which are answered by the students as preparation for the lecture. After planning the in-class activities, the teacher uses the answers just before his lecture to adapt his teaching agilely to the answers of the students. Thus, the students are recognized as essential participants in the development of face-to-face time [21]. Vogel, Kilamo, and Kurti describe the development of two courses closing the gap between academic education content and industrial demands in the field of software development. In one course, they used Scrum as a basis for the course structure. Scrum is based on the empirical process control theory. All participants included in the Scrum process are combined in the so-called Scrum Team: The Product Owner, the Scrum Master, and the Development Team [10]. The Scrum process has a specific sequence and begins with the Product Owner in a planning phase [22]. He or she is one person who is making the essential decisions of the project and is defining all the requirements [10]. The Product Owner's vision of the entire product is initially documented in the Product Backlog. The Product Owner now selects precisely those requirements that should be implemented in one Sprint, creating the Sprint Backlog [23]. Hereupon the Sprint 
starts, and the Development Team begins to evolve the product. One sprint takes about 30 days and has a fixed goal about what to fabricate [22]. It consists of a Sprint Planning Meeting, a Daily Scrum, the development work, a Sprint Review meeting, and a Sprint Retroperspective meeting. At the end of the Sprint there is the Product Increment, a functional intermediate product of the Product Backlog [10]. Vogel, Kilamo, and Kurti followed this process developing their FC. For the other course, they conducted an FC, in which online material for preparation as well as questions were previously addressed to the students. The answers of the students to these questions were then used to design the discussion that took place during face-to-face-time [19]. This procedure points to similarities with JiTT, even though the authors do not mention this method by name. The research of Gale et al. research is based on the Ebola outbreak calling for new learning methods because of time and place restrictions of training staff, difficult access to health staff, and limited financial resources. Using Scrum, the authors were able to produce training content as an online-simulation for three months. They adapted the Scrum process to their case-specific needs. Gale et al. point out that the resulting online material could be used within an FC by deepening important content in local workshops [20]. Bofill appoints time limit during the semester, missing adjustment of module contents and strong limitation of time for e-learning development as existing framework conditions at Florida International University Herbert Wertheim College of Medicine in the subject Radiology. She combined the instructional design (ID) model ADDIE with rapid prototyping to create e-learning material efficiently [4]. Along with this, other authors are also calling for important aspects of instructional design to be taken into account when developing an FC $[12,24]$. However, it is a challenge to adapt existing ID models or to develop new ID models that seem suitable for the development of digital teaching concepts [25]. In Bofill's research, ADDIE delivers a framework to design a curriculum [26] while fast prototyping allows reverse loops and a corresponding adaptation during the development process [4].

As the findings show, a general model concerning the particularities of agile FC Development does not exist yet. Taking a closer look at the articles, it becomes clear that the minority explicitly deal with agile FC development. Instead, they deal with agile blended learning or e-learning development. Currently, literature provides only a few clues as to how agile FC development should take place. No holistic view of the development of an FC lecture has been taken into account yet, as some authors focus mainly on the development of online materials $[4,20]$, while others are primarily concerned with the design of the presence phase [18, 19]. In addition, general principles for agile development have already been addressed [8]. But a model for agile FC development in HEI considering both, the development of online materials and face-toface time, is still pending. We, therefore, want to fill this research gap, answering our RQ2 in the next section. 


\section{Design of an Agile ${ }^{\mathrm{FC}}$ Development Model}

The results of the literature review and the more detailed investigation of the applied agile concepts lead us to the design of the Agile ${ }^{\mathrm{FC}}$ Development Model. We claim that no agile concept listed in Table 1 is suitable on his own to design a general FC course nor a single FC Lecture. Although certain methods are suitable for particular phases of FC, such as video development, none of them have been used for the development of the entire course so far. We are instead of the opinion that those agile concepts should complement each user. Thus, we designed a model regarding key features of agile concepts used in the included articles. In order to allow teachers a flexible development of an FC course, the model refers to the development of individual FC lectures instead of the development of the whole course. Thus, teachers can decide whether they want to transform one, several or all events into an FC during one or more semesters. As a result, our Agile ${ }^{\mathrm{FC}}$ Development Model for FC lectures is shown in Fig. 3. The model illustrates the creation of a single one-week session. Since an entire course consists of numerous sessions, the development model has to be run through several times in order to develop a whole FC course. Both, the agile principles [8] and the consideration of relevant ID aspects $[4,24]$, form the foundation of the Agile ${ }^{\mathrm{FC}}$ Development Model. But since our model is designed to provide efficient and practical guidance for agile development of an FC, neither is considered in depth. Moreover, the model is a combination and generalization of Scrum and JiTT. The Agile ${ }^{\mathrm{FC}}$ Development is to be separated into two parts: The online activities of the self-study phase and the in-class activities. For the first part, we made use of Scrum. In Fig. 3, this is shown by the first four steps of the model, starting with the Product Backlog and ending with the Finished Milestone. Unlike the classic Scrum process, roles in our model are distributed to stakeholders in the HEI. A Product Owner could be, e.g., a professor or a team leader of a special digitalization project. The Scrum Master could be a responsible researcher of the department. According to existing capacities, we claim for an interdisciplinary Development Team containing researchers, employed students, and IT-staff with knowledge concerning digital learning and technical implementation.

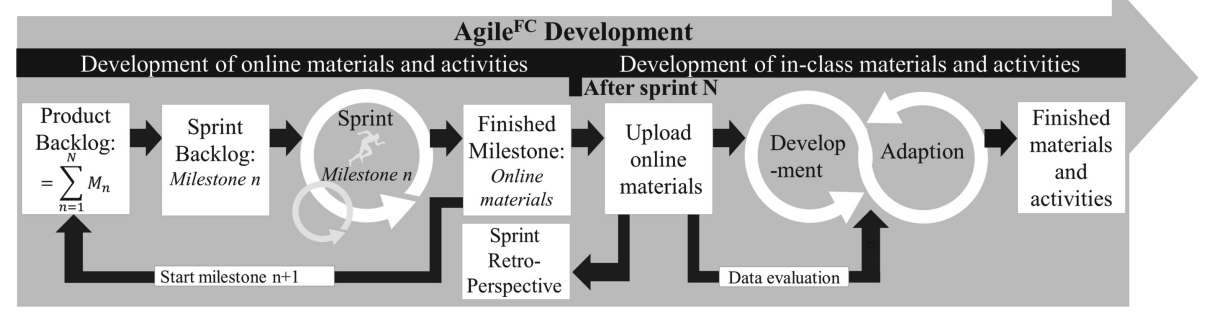

Fig. 3. Agile ${ }^{\mathrm{FC}}$ development model

The model itself starts with the Product Backlog of Scrum, given by the overall requirements for FC development. The Product Backlog is to develop the online materials for a single one-week long FC course. In the following, the requirements are 
divided into several milestones (M), which all have to be mastered in order to develop the materials. Each milestone represents a new Sprint Backlog. The Product Backlog is therefore given by $\sum_{n=1}^{N} M_{n}$ with $\mathrm{n}=1, \ldots, \mathrm{N}$. A milestone is processed during each sprint sequence. For the development of an FC course, it is recommended to adopt Scrum by shortening the time of a sprint to one week, as the case study of Gale et al. shows [20]. Similar to the classic Scrum, the Sprint also includes daily Sprints. After a milestone has been completed, the Scrum Process starts again at the Product Backlog. The development of online materials is finished, when the last milestone $\mathrm{N}$ of the Product Backlog has been implemented, which means that the online materials for this single course are completely developed. Following the first phase, the materials produced are made available online to the students. The Sprint Retroperspective meeting will then take place hereafter. Due to the shortened sprint times and the fact that every sprint has a Review meeting itself, there is no need to do hold a Sprint Retroperspective meeting after every milestone- Sprint. Instead, the results of this meeting will be used for the online material development of the next Product Backlog at the next one-week session. Moreover, in this way, not only the evaluation of the Scrum Team but also an evaluation of the students and other stakeholders can flow into the next session production of online materials.

Once the materials are available online, the second phase of the Agile ${ }^{\mathrm{FC}}$ Development Model begins: The in-class material and activity development. This is aimed at the presence phase of the FC. Two of our included articles made use of JiTT or a JiTT similar procedure to adjust their presence phase on students' responses [18, 19]. JiTT is attributed with a positive effect on the learning success of students [18]. In order to use this effect and to ensure that agility is consistently applied in our model, we adopt this approach for the design of the presence phase, so that a flexible adaption to the respective students is possible. To apply JiTT in the following development process, it is necessary to produce at least one online-activity offering questions to the students that can be evaluated to adopt already developed learning activities according to student needs. At this point, the teacher is in charge of creating the content for in-class time. During this, he could make use of an ID, such as ADDIE. After evaluating the questions asked in the online phase before, he or she is able to adapt the materials according to JiTT. For the FC, this means that the materials for the in-class time are improved on the basis of the data evaluation from the self-tests and quizzes provided online. This has to be done short notice as a circle between development and adaptation. It allows the teacher to respond flexibly to the current needs derived from the answers of the students and to interpret them in the class time accordingly. This also means that the development of materials is only completed shortly before the beginning of the lecture. Further on, in-class activities also follow the circle of development and adaption and can be designed in a variety of ways. For example, open elements such as live questionnaires or discussions that influence the structure of the lecture on site can be integrated. During this phase, it lends itself to retain the roles previously defined. Thus, the Product Owner could set the essential goals, the Development Team could take over the data evaluation, and the Scrum Master could carry out the didactic implementation. Daily meetings are also recommended due to the fast-paced nature of the in-class time development. In a nutshell, the Agile ${ }^{\mathrm{FC}}$ Development Model is a combination of different agile approaches, most of all Scrum and JiTT, that has been transferred and adapted to the context of FC development at HEI. 


\section{Application of the Agile ${ }^{\mathrm{FC}}$ Development Model}

In order to show one possible application of our Agile ${ }^{\mathrm{FC}}$ Development Model, we conducted a short case study by flipping one course as a prototype in which two of the authors were actively involved as Scrum Masters and one as a Product Owner. Within this case study, the module "Fundamentals of Organization" of the bachelor's degree program in economics at a German public university is supposed to be transformed from a traditional lecture into an FC course. This was carried out as part of a study project in the summer term 2019. As mentioned above, it is advisable to implement an FC step-by-step [12, 13]. Also, referring to our model, a stepwise implementation is recommended, as lecturers need some time to overcome barriers of change and get used to the new methods like JiTT [21]. Also, in our case, an abrupt change to an FC using the Agile ${ }^{\mathrm{FC}}$ Development Model for each lecture date does not seem feasible due to a lack of time and personnel. For this reason, we defined different levels of FC implementations to convert the module gradually. Four levels are required for the entire course transformation. Figure 4 visualizes level 1, conducted 2019 and explained below, as well as level 2, planned for 2020. The following levels will be continued accordingly until all sessions are transformed.

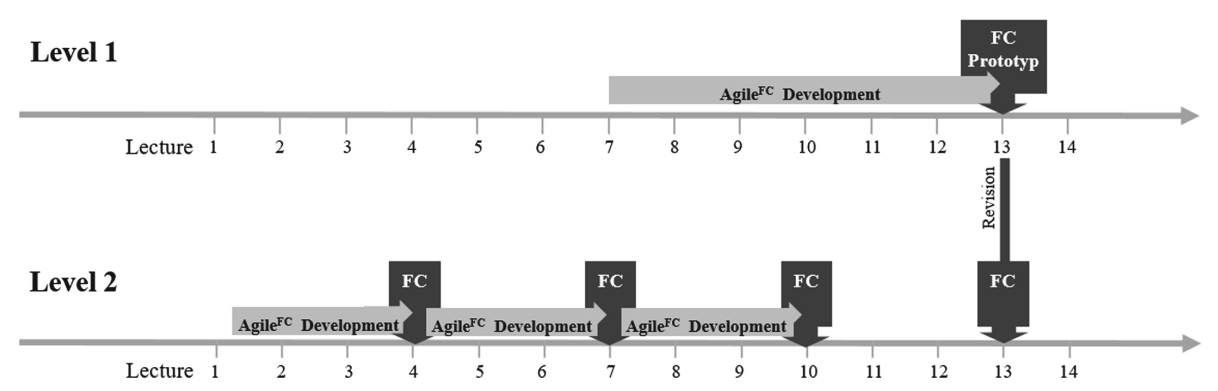

Fig. 4. Level 1 and 2 of Agile ${ }^{\mathrm{FC}}$ development

We started the application of our model in the middle of the semester using Scrum to develop videos and questions to generate online-activities and using JiTT to adapt in-class-activities to student's needs. The Scrum process of our model lasted five weeks until the 12th lecture when we uploaded the online material in our learning management system. JiTT was used during the 12th and 13th lecture, where the FC prototype took place. The Scrum Team of our development process consisted of the professor of the course, two research assistants, and three master students. The professor was the Product Owner of the project. He defined the Product Backlog, one session of FC course. He also decided about the type, scope, and design of the FC prototype. The research assistances, two authors of this paper, were the Scrum Masters, as they coordinated the activities of the Development Team and monitored the prototype development. We occupied this role twice to allow as many people as possible to benefit from the experience to facilitate the ongoing agile development process. Furthermore, the master students of the project seminar build the Development Team. 
At the beginning of the process, an overview of project goals was formulated. We defined the milestones for each sprint as follows: (1) formulating learning objectives, (2) writing a storyboard for a video, (3) creating slides for the video, (4) formulating questions for online practice, quizzes, and online self-testing and (5) produce the video. At the end of each sprint, there was a weekly meeting with the whole Scrum Team, where the Development Team presented their results. Each meeting was related to one milestone. After discussing potential problems, the Scrum Teams adjusted the milestones as appropriate. In this way, the Development Team had a fixed date when which milestone had to be fulfilled. Since the meeting within the Scrum Team was held not daily, but rather weekly, we stayed in contact via social media to enable daily communication. In addition, Scrum Masters conducted every morning a short, approximately 15 min daily Scrum to support the Development Team whenever necessary. Short-term problems were solved in this way. After the last milestone, we held the Sprint Review meeting and reflected the project. This meeting concluded all five sprints we conducted for each milestone. After this, the production of the online materials for the prototype was finished, whereupon they were uploaded online. These were available to the students between the 12th and 13th lecture to prepare for the 13th lecture. Meanwhile, we developed the materials for the in-class time. In doing so, the online questions and quizzes were directly incorporated into the adaptation and influenced the focus of our content. In this way, we were able to respond to the needs of the students and clarify their questions better during the FC presence phase at the 13th lecture. In addition, a quantitative survey of the students was carried out to evaluate the prototype. The results of this survey were discussed in the Retroperspective Meeting. Hereafter, level 1 of agile FC development was finalized. We have planned the same process for lecture 4, 7 and 10 in level 2. Due to learning effects, we assume that less time is needed for development in the future. The 13th lesson of level 1 will be revised and improved in level 2 based on the results of the evaluation. In addition, the online questions of the current semester will continue to be incorporated into the revision of the course content. In the following semesters, we plan to increase the number of sessions to be developed, as shown in Fig. 4. At the end of level 4, the course is fully transformed into an FC, as illustrated in Fig. 5.

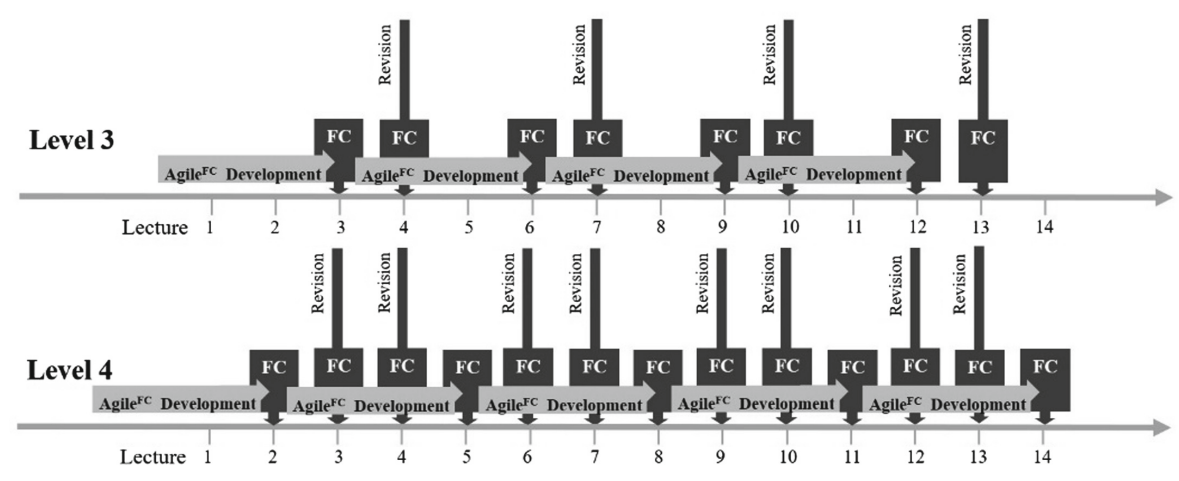

Fig. 5. Level 3 and 4 of Agile ${ }^{\mathrm{FC}}$ development 


\section{Conclusion}

The aim of our work is to provide teachers with an understanding of the possible use of agile methods for designing FCs based on current research. For this purpose, we have developed a model that includes different agile methods. We assume that both teachers and students can benefit from our model, because following Scrum, a structured and time-saving development takes place, and following JITT, learner-centered and individual learning processes are made possible. To introduce the topic and an overview of the current state of research on the subject, we first conducted a structured literature review. Our review resulted in five research articles that make agile concepts in education a subject of discussion. There is no generally applicable agile model for FCs in current research. Thus, we filled the research gap evolving the Agile ${ }^{\mathrm{FC}}$ Development Model, referring to our findings. This model is a combination of different agile approaches, most of all Scrum and JiTT. To illustrate how to implement the Agile ${ }^{\mathrm{FC}}$ Development Model in practice, we introduced a case study of an FC development. We suggest a stepwise implementation of an FC course, beginning with one prototype of one single course and continuing gradually with the other sessions as a classic lecture.

Even though we conducted our research systematically and conscientiously, it may have limitations. Another research process could have led to other or more findings. Our model is based on the literature available through the literature review and our experiences as FC developers. Other experienced FC developers could have rated different concepts as relevant and suitable for an Agile $^{\mathrm{FC}}$ Development Model. In addition, a general model, as we wanted to create, could be in contrast to the individuality of the course conditions. Depending on the course, further adjustments could be necessary. On the other hand, the shown application of the model is case-based and referred to our course and, therefore, not necessarily transferable to other HEI without adaptation. The boundaries of our work indicate the need for further research. During continuing the development process of our course, we would like to evaluate and adapt our Agile ${ }^{\mathrm{FC}}$ Development Model. In particular, we want to investigate whether an agile and stepwise approach to the development of an FC can increase acceptance by teachers and other stakeholders. We also plan to use the results of our evaluation for continuous improvement in the agile sense.

\section{References}

1. Bergmann, J., Sams, A.: Flip Your Classroom: Reach Every Student in Every Class Every Day. International Society for Technology in Education, Alexandria (2012)

2. Bishop, J.L., Verleger, M.A.: The flipped classroom: a survey of the research. In: ASEE National Conference Proceedings, Atlanta, GA, pp. 1-18 (2013)

3. Giannakos, M.N., Krogstie, J., Chrisochoides, N.: Reviewing the flipped classroom research: reflections for computer science education. In: Proceedings of the Computer Science Education Research Conference, pp. 23-29. ACM, New York (2014)

4. Bofill, L.: The design and implementation of online radiology modules using the ADDIE process and rapid prototyping (2016) 
5. Liebscher, J., Petschenka, A., Gollan, H., Heinrich, S., van Ackeren, I., Ganseuer, C.: E-Learning-Strategie an der Universität Duisburg-Essen - mehr als ein Artefakt? ZFHE 10, 93-109 (2015)

6. Beck, K., et al.: The agile manifesto (2001)

7. Conboy, K., Fitzgerald, B.: Toward a conceptual framework of agile methods. Presented at the Conference on Extreme Programming and Agile Methods (2004)

8. Tesar, M., Sieber, S.: Managing blended learning scenarios by using agile e-learning development, vol. 5, pp. 125-129 (2010)

9. Johnson, L.: NMC horizon report: 2014 higher education edition. NMC (2014)

10. Schwaber, K., Sutherland, J.: The scrum guide-the definitive guide to scrum: the rules of the game (2013)

11. Sharp, J.H., Lang, G.: Agile in teaching and learning: conceptual framework and research agenda. J. Inf. Syst. Educ. 29, 1 (2019)

12. Hurtubise, L., Hall, E., Sheridan, L., Han, H.: The flipped classroom in medical education: engaging students to build competency. J. Med. Educ. Curric. Dev. 2, 35-43 (2015)

13. Harris, B.F., Harris, J., Reed, L., Zelihic, M.: Flipped classroom: another tool for your pedagogy tool box, pp. 325-333 (2016)

14. Owen, H., Dunham, N.: Reflections on the use of iterative, agile and collaborative approaches for blended flipped learning development. Educ. Sci. 5, 85-103 (2015)

15. Schryen, G.: Writing qualitative IS literature reviews-guidelines for synthesis, interpretation, and guidance of research. Commun. Assoc. Inf. Syst. 37, 286-325 (2015)

16. Webster, J., Watson, R.T.: Analyzing the past to prepare for the future: writing a literature review. Manag. Inf. Syst. Q. 26, xiii-xxiii (2002)

17. Hult, M., Lennung, S.-Å.: Towards a definition of action research: a note and bibliography. J. Manage. Stud. 17, 241-250 (1980)

18. Meissner, B., Stenger, H.-J.: Agiles Lernen mit Just-in-Time-Teaching. Teaching Trends, pp. 121-136 (2014)

19. Vogel, B., Kilamo, T., Kurti, A.: Teaching distributed agile development to software professionals: a flexible approach. In: Proceedings of the 2015 European Conference on Software Architecture Workshops, p. 31. ACM (2015)

20. Gale, T.C., Chatterjee, A., Mellor, N.E., Allan, R.J.: Health worker focused distributed simulation for improving capability of health systems in Liberia. Simul. Healthc. 11, 75-81 (2016)

21. Novak, G.M.: Just-in-time teaching. New Dir. Teach. Learn. 2011, 63-73 (2011)

22. Schwaber, K.: Scrum development process. In: Sutherland, J., Casanave, C., Miller, J., Patel, P., Hollowell, G. (eds.) Business Object Design and Implementation, pp. 117-134. Springer, London (1997)

23. Sharma, S., Hasteer, N.: A comprehensive study on state of Scrum development. Presented at the 2016 international conference on computing, communication and automation (ICCCA) (2016)

24. Hoffman, E.S.: Beyond the flipped classroom: redesigning a research methods course for eInstruction. Contemp. Issues Educ. Res. 7, 51-62 (2014)

25. Enkenberg, J.: Instruction design and emerging teaching models in higher education. Comput. Hum. Behav. 17, 495-506 (2001)

26. Hodell, C.: Instructional systems and the ADDIE model. In: ISD From the Ground Up, 2nd edn. Association for Talent Development, Alexandria (2006) 